East African Medical Journal Vol. 77 No. 5 May 2000

KNOWLEDGE, SELF-EFFICACY, AND BEHAVIOURAL INTENT TOWARDS AIDS PREVENTION BEHAVIOURS AMONG CULTURALLY DIVERSE SECONDARY SCHOOL PUPILS IN SOUTH AFRICA

K. Peltzer, PhD, Department of Psychology, L. Cherian, PhD and V.I. Cherian, PhD, Department of Psychology of Education, University of the North, Private Bag X1106, Sovenga 0727, South Africa.

Request for reprints to: Professor K. Peltzer, Department of Psychology, University of the North, Private Bag X1106, Sovenga 0727, South Africa

\title{
KNOWLEDGE, SELF-EFFICACY AND BEHAVIOURAL INTENT TOWARDS AIDS PREVENTION BEHAVIOURS AMONG CULTURALLY DIVERSE SECONDARY SCHOOL PUPILS IN SOUTH AFRICA
}

\section{K. PELTZER, L. CHERIAN and V.I. CHERIAN}

\begin{abstract}
Objective: To investigate knowledge, self-efficacy, and behavioural intent towards AIDS prevention behaviours among culturally diverse secondary school pupils in South Africa. Design: Randomised study.

Setting: Three urban secondary schools in Pietersburg, South Africa.

Participants: Three hundred and sixty six Grade 11 secondary school pupils, comprising 150 (41\%) males, and 216 (59\%) females, aged 17 to 24 years (mean age 19.3 years, $\mathrm{SD}=2.6$ ). The three cultural groups were 142 Blacks, 112 Whites and 112 Asians.

Main outcome measures: The questionnaire included items on socio-economic and family background, knowledge about HIV, perceived self-efficacy and behavioural intent regarding AIDS preventive behaviours.

Results: Overall, the participants showed an adequate level of AIDS knowledge. However, there was considerable inaccuracy regarding AIDS transmission myths or how AIDS cannot be transmitted. The different cultural groups generally felt most self- efficacious regarding how to protect themselves from becoming infected (75-90\%) and least self-efficacious on knowing where to go for information on AIDS (72-74\%). Generally, participants reported a high behavioural intent. The Whites stand second in knowledge and more or less second in self-efficacy and behaviour intent. The Blacks stand third in knowledge and more or less second in self-efficacy and behaviour intent.

Conclusion: Culturally diverse knowledge, self-efficacy and behavioural intent towards AIDS prevention was found among White, Black and Asian pupils, which should inform a culturally sensitive and appropriate AIDS health promotion programme in South Africa.
\end{abstract}

\section{INTRODUCTION}

South Africa is facing an escalation of reported AIDS cases. It is expected that the prevalence of AIDS will reach about $25 \%$ of the total adult population in South Africa by the year 2010(1). At least half of those infected with HIV are under the age of 25, making AIDS a major concern affecting youth today(2). A number of investigations with the inventory knowledge, attitude and practice on different populations such as the general population, black parents, residents of informal settlements, students attending tertiary institutions and hostel dwellers found a general lack of knowledge and also false information on HIV and AIDS(2). The socio-cultural context of HIV/AIDS in South Africa differs. Therefore, AIDS prevention messages should be guided by research in culturally diverse populations. Yet there has been limited research aimed at understanding factors associated with AIDS preventive and risky behaviours among different cultural groups in South Africa.

The purpose of this study was to describe the level of AIDS knowledge, self-efficacy, and behavioural intent regarding HIV-preventive and risky behaviours in a culturally diverse sample of South African secondary school pupils. An earlier study suggests that different cultural adolescent groups in South Africa have a fairly high level of knowledge about AIDS(3). It appears that knowledge about AIDS may be important but not sufficient by itself to change behaviours. Knowledge and selfefficacy were expected to influence behavioural intent and were conceptualised as independent variables. Behavioural intent was conceptualised as the dependent variable, since the intention to engage in HIV-preventive behaviour increases the likelihood to engage in safer and less risky actions incorporating some of the components of the theory of reasoned action(4) and the self-efficacy theory(5). 


\section{MATERIALS AND METHODS}

Sample: The sample included Grade 11 secondary school pupils chosen at random from three urban schools in Pietersburg. The pupils were $150(41 \%)$ males, and $216(59 \%)$ female, in the age range of 17 to 24 years (mean age 19.3 years, $S D=2.6$ ). The three cultural groups were 142 Blacks, 112 Whites and 112 Asians.

Instruments: The questionnaire included ten items on socioeconomic background: age, sex, religion, ethnicity, occupation, education and income of parents, and four items on family background: parental status, family size, birth order.

Eight items made up a scale assessing knowledge of myths and facts about HIV transmission and behaviours that reduce the risk of transmission. Participants responded to items by circling yes, no, or don't know. Two points were assigned for each correct answer, this, knowledge scores could range from 8 (lowest level of knowledge) to 16 (highest level of knowledge). Three items on perceived self-efficacy assessed whether or not the respondent felt that he or she had the ability to engage in
AIDS preventive behaviours (Appendix 1). Each yes response was scored as 2 points. The scores could range from 3 (low perceived self-efficacy) to 6 (high perceived self-efficacy). Eight behavioural-intent items had the aim of assessing subjects' reported intentions to behave in ways that would prevent or decrease the risk of contracting AIDS. Participants respondent by circling yes, no, or don't know to each item. A composite behavioural intent score summed up the yes responses. Scores could range from 8 (low behavioural intent) to 16 (high behavioural intent) (6).

\section{RESULTS}

Participants' responses to knowledge items are shown in Table 1. Overall, the participants showed an adequate level of AIDS knowledge. However, there was considerable inaccuracy regarding AIDS transmission myths or how AIDS cannot be transmitted. For example, more than $45 \%$

Table 1

Percentage of Yes, No, and Don't know responses for knowledge, self-efficacy, and behavioural intent items

\begin{tabular}{|c|c|c|c|c|}
\hline Item & Category & Blacks & Whites & Asians \\
\hline \multicolumn{5}{|l|}{ Knowledge } \\
\hline Can a person get HIV infection from being bitten by & Yes & 22.8 & 8 & 30.1 \\
\hline mosquitoes or other insects? & No; $*$ & $68.4 ; 8.3$ & $79.5 ; 12.5$ & $65.7 ; 4.2$ \\
\hline \multirow[t]{2}{*}{ Can a person get HIV infection from donating blood? } & Yes & 38.7 & 45.5 & 15.4 \\
\hline & No; $*$ & $54.5 ; 6.8$ & $46.4 ; 8.0$ & $80.4 ; 4.2$ \\
\hline \multirow[t]{2}{*}{ Can a person get HIV infection from having a bloodtest? } & Yes & 25.2 & 25 & 12.6 \\
\hline & No; * & $66.8 ; 8.1$ & $64.3 ; 10.7$ & $83.2 ; 4.2$ \\
\hline \multirow[t]{2}{*}{ Can a person get HIV infection from using public toilets? } & Yes & 16.0 & 5.4 & 16.8 \\
\hline & No; $*$ & $77.4 ; 6.6$ & $82.0 ; 12.6$ & $83.2 ; 0$ \\
\hline Can a person get HIV infection from having sexual & Yes & 91.00 & 95.5 & 90.2 \\
\hline intercourse without a condom(rubber)? & No; $*$ & $8.1 ; 0.9$ & $3.6 ; 0.9$ & $9.8 ; 0$ \\
\hline \multirow[t]{2}{*}{ Is there a cure for AIDS/HIV infection? } & Yes & 16.40 & 5.4 & 13.3 \\
\hline & No; $*$ & $75.2 ; 8.4$ & $91.1 ; 3.6$ & $82.5 ; 4.2$ \\
\hline Can people reduce their chances of being infected with & Yes & 74.4 & 87.5 & 74.8 \\
\hline the HIV virus by using condoms during sexual intercourse?. & No; $*$ & $17.6 ; 8.0$ & $9.8 ; 2.7$ & $21.0 ; 4.2$ \\
\hline Can people reduce their chances of being infected with the HIV virus by not & Yes & 68.9 & 67.6 & 83.9 \\
\hline having anykind of sexual intercourse with a person who has injected drugs? & No; $*$ & $15.5 ; 15.5$ & $18.0 ; 14.4$ & $6.3 ; 9.8$ \\
\hline \multicolumn{5}{|l|}{ Self-efficacy } \\
\hline \multirow[t]{2}{*}{ I know how to protect myself from becoming infected. } & Yes & 83.2 & 75.7 & 90.9 \\
\hline & No $*$ & $9.6 ; 7.1$ & $18.0 ; 6.3$ & $4.9 ; 4.2$ \\
\hline \multirow{2}{*}{$\begin{array}{l}\text { I know where to go for more information on } \\
\text { preventing AIDS. }\end{array}$} & Yes & 73.7 & 74.1 & 72 \\
\hline & No* & $19.5 ; 6.8$ & $18.8 ; 7.1$ & $23.8 ; 4.2$ \\
\hline \multirow[t]{2}{*}{ I know how to use condoms. } & Yes & 79.1 & 73.9 & 83.9 \\
\hline & No; $*$ & $12.8 ; 8.1$ & $16.2 ; 9.9$ & $11.9 ; 4.2$ \\
\hline \multicolumn{5}{|l|}{ Behavioural intent } \\
\hline \multicolumn{5}{|l|}{ Based on what I know about AIDS I will: } \\
\hline \multirow[t]{2}{*}{ postpone sexual activity. } & Yes & 63 & 57.1 & 69.9 \\
\hline & No; $*$ & $19.7 ; 17.2$ & $19.6 ; 23.2$ & $21.7 ; 8.4$ \\
\hline \multirow[t]{2}{*}{ use condoms or request that my partner use them. } & Yes & 87.3 & 90.0 & 92.3 \\
\hline & No; * & $6.5 ; 6.2$ & $7.3 ; 2.7$ & $2.1 ; 5.6$ \\
\hline \multirow[t]{2}{*}{ change my sexual behaviour. } & Yes & 77 & 64.2 & 91.6 \\
\hline & No; * & $11.5 ; 11.5$ & $21.7 ; 14.2$ & $2.1 ; 6.3$ \\
\hline not engage in sexual activity after drinking or taking & Yes & 70.8 & 61.8 & 91.6 \\
\hline drugs. & No; $*$ & $15.2 ; 13.7$ & $20.0 ; 17.3$ & $4.2 ; 4.2$ \\
\hline ask some one about their sexual history before having. & Yes & 81.8 & 76.6 & 89.5 \\
\hline sex with them. & No; $*$ & $10.4 ; 7.9$ & $14.0 ; 9.3$ & $4.2 ; 6.3$ \\
\hline \multirow[t]{2}{*}{ not share needles with anyone. } & Yes & 85.8 & 92 & 88.8 \\
\hline & No; $*$ & $7.4 ; 6.8$ & $6.3 ; 1.8$ & $4.2 ; 7.0$ \\
\hline \multirow[t]{2}{*}{ talk to my partner about safer sexual behaviour } & Yes & 87.6 & 93.7 & 90.9 \\
\hline & No; $*$ & $5.9 ; 6.5$ & $3.6 ; 2.7$ & $2.1 ; 7.0$ \\
\hline \multirow[t]{2}{*}{ not engage in sexual activity with more than person. } & Yes & 70.6 & 100 & 76.2 \\
\hline & No; * & $6.2 ; 23.2$ & & $2.1 ; 21.7$ \\
\hline
\end{tabular}


of the Whites and 38\% of the Black pupils reported that one could get HIV from donating blood and more than $30 \%$ Asians and 22\% Black pupils felt that HIV infection could be spread by being bitten by mosquitoes or other insects. The sample fared better on their knowledge about how HIV could be transmitted. For example, more than $90 \%$ of all cultural groups reported that one can get HIV from having sexual intercourse without a condom. The participants' responses to self-efficacy items are also shown in Table 1 . The different cultural groups generally felt most self-efficacious regarding how to protect themselves from becoming infected (75-90\%) and least self-efficacious on knowing where to go for information on AIDS (72-74\%). Participants' responses to behaviouralintent items are shown in Table 1. Generally, participants reported a high behavioural intent. For example, around $60 \%$ reported that they would postpone sexual activity, $80 \%$ would ask someone about their sexual history before having sex with them, and around $90 \%$ would use condoms or request that their partner use condoms. A hundred per cent of the Whites reported that they - on the basis of what they know about AIDS - will not engage in sexual activity with more than one person, whereas only $70 \%$ of the Blacks and $76 \%$ of the Asians indicated so.

Table 2

Means and standard deviations for knowledge, self-efficacy, and behavioural intent scales by culture

\begin{tabular}{lllr}
\hline & Black $(\mathrm{n}=142)$ & White $(\mathrm{n}=112)$ & Asians $(\mathrm{n}=112)$ \\
\hline Sub scale & M (SD) & M (SD) & M (SD) \\
Knowledge & $3.70(1.57)$ & $6.11(1.45)$ & $6.44(2.39)$ \\
Self-efficacy & $2.38(0.82)$ & $2.22(0.90)$ & $2.58(0.70)$ \\
$\begin{array}{l}\text { Behavioural } \\
\text { intent }\end{array}$ & $5.04(1.94)$ & $5.26(1.60)$ & $7.21(1.42)$ \\
\hline
\end{tabular}

Table 2 indicates the following: Black's mean score of $3.70(\mathrm{SD}=1.57)$ is significantly lower than the mean score $6.11(\mathrm{SD}=1.45)$ for the White $(\mathrm{F}=3.8, \mathrm{p}<.05)$ and the mean score $6.44(\mathrm{SD}=2.39)$ for the Asians $(\mathrm{F}=11.0$, $\mathrm{p}<.001)$. There was no significant difference between the mean scores for the Whites and the Asians. Asians and Whites can be placed in rank 1 and the Blacks in rank 3 in their knowledge of AIDS.

There is no statistically significant difference between the mean self-efficacy score of $2.38(\mathrm{SD}=0.85)$ for Blacks and the score of $2.22(\mathrm{SD}=0.90)$ for the Whites. The self efficacy score $2.58(\mathrm{SD}=0.7)$ for the Asians is significantly higher than that of $2.22(\mathrm{SD}=0.9)$ for the Whites $(\mathrm{F}=42.9$, $\mathrm{p}<.0001)$ and that of $2.38(\mathrm{SD}=0.82)$ for the Black $(\mathrm{F}=42.3$, $\mathrm{p}<.0001)$.

The behaviour intent score $5.26(\mathrm{SD}=1.6)$ for the Whites is significantly lower than that of $7.21(\mathrm{SD}=1.42)$ for the Asians $(\mathrm{F}=19.2, \mathrm{p}<0.002)$. There is no significant difference between the behaviour intent scores for the Blacks and the Whites. Asians behaviour intent score of $7.21(\mathrm{SD}=1.42)$ is significantly higher than the score of $5.04(\mathrm{SD}=1.44)$ for the blacks $(\mathrm{F}=24.9, \mathrm{p}<0.0001)$.
Asians stand first in knowledge, self efficacy and behaviour intent. The Whites stand second in knowledge and more or less second in self efficacy and bahaviour intent. The Blacks stand third in knowledge and more or less second in self efficacy and behaviour intent.

Table 2 indicates that among Blacks and Asians selfefficacy has a stronger relationship with behavioural intent than that of knowledge. Self-efficacy is related to behavioural intent for all the cultural groups whereas knowledge is not related to behavior intent for the White pupils. Female gender is related to behaviour intent only for the White cultural group.

\section{Table 3}

Stepwise multiple regression to determine the unique contribution of each independent variable (knowledge, self-efficacy, age, gender, SES) on behavioural intent

\begin{tabular}{llllll}
\hline Step & $\begin{array}{l}\text { Independent } \\
\text { variable }\end{array}$ & $\begin{array}{l}\text { Dependent } \\
\text { variable }\end{array}$ & $\mathrm{R}$ & $\mathrm{P}<$ & $\mathrm{N}$ \\
\hline & Black pupils & & & & 142 \\
1. & Self-efficacy & Behavioural intent & 0.38 & 0.0001 & \\
2. & Knowledge & & 0.48 & 0.0001 & \\
& White pupils & & & & 112 \\
1. & Gender & Behavioural intent & 0.24 & 0001 & \\
2. & Self-efficacy & & 32 & 0001 & \\
& Asian pupils & & & & 112 \\
1. & Self-efficacy & Behavioural intent & 0.36 & 0.0001 & \\
2. & Knowledge & & 39 & 0.0001 & \\
\hline
\end{tabular}

Table 3 indicates the results of stepwise multiple regression on the relationship of knowledge, self efficacy, age, gender and SES with behaviour intent. For black pupils self efficacy and knowledge together has a multiple correlation of $0.48(\mathrm{p}<0.0001)$ which is higher than that of 0.39 for the Asian pupils ( $\mathrm{p}<0.0001$ ). For White pupils gender and self efficacy were the independent variables that had a multiple correlation of 0.32 with behaviour intent $(\mathrm{p}<0.0001)$, knowledge has no correlation with behaviour intent.

\section{DISCUSSION}

The sample of South African secondary school pupils showed a similar level of knowledge regarding HIV transmission and behaviours that reduce the risk of transmission and a similar fair degree of inaccuracy regarding transmission myths or how AIDS cannot be transmitted as compared to samples of secondary school pupils in other African countries such as Kenya, Malawi and South Africa (3,7-9) except for Zimbabwean secondary school pupils where the large majority were not aware about the mode of transmission of AIDS (10).

This study did not find any significant differences on the knowledge regarding HIV transmission and behaviours across cultures, which is different to a study conducted among Black and White American adolescents where Blacks compared to Whites were found to have almost twice as likely to have misconceptions regarding transmission of AIDS (11). 
Self-efficacy was positively correlated with behavioural intent across all cultural groups, which was also found in African Americans(6). Knowledge was not associated with behavioural intent in the latter study and among Whites.

Coefficient of concomittance $\left(\mathrm{r}^{2}=0.23\right)$ indicates that the joint contribution of self efficacy and knowledge to behaviour intent for Black pupils is $23 \%$ whereas that for Asian pupils is $15 \%$. For White pupils knowledge does no contribute to behaviour intent, only gender and self efficacy contribute jointly to ten per cent of behaviour intent.

One practical implication is that education and prevention efforts should in particular in the White group apart from knowledge among the African and Asian groups - focus on skill acquisition so that persons will become selfefficacious in their beliefs about HIV prevention.

The study found different results among culturally diverse samples, which form the basis for socio-culturally informed health promotion interventions. For example, a hundred per cent of the Whites reported that they - on the basis of what they know about AIDS will not engage in sexual activity with more than one person, whereas only $70 \%$ of the Blacks and $76 \%$ of the Asians indicated so. There is a need to address cross-cultural validity(12) and a full understanding of the cultural and social context of health of HIV/AIDS for prevention efforts(13). As a conclusion, a conceptual model for health promotion in South Africa must address cultural sensitivity and cultural appropriateness in programme development(14).

\section{ACKNOWLEDGEMENTS}

We thank the University of the North for financial support and the Provincial Department of Education for giving us permission to conduct this study.

\section{REFERENCES}

1. Slawski, J.K. Some aspects of AIDS in the work place. Occup. Health S. Afr. 1996; 2: 12-14.

2. Lindegger, G., and Wood, G. The AIDS crisis: review of psychological issues and implications, with special reference to the South African situation. S. Afri. J. Psych. 1995; 25: 1-11.

3. Peltzer, K., Cherian, L., and Cherian, V.I. AIDS awareness of secondary school pupils in the Northern Province of South Africa. Psychological Reports 1998; 83: 955-958.

4. Ajzen, I., and Fishbein, M. Understanding attitudes and predicting behaviour. Engelwood Cliffs, NJ: Prentice-Hall 1980.

5. Ajzen, I., and Madden, T.J. Prediction of goal-directed behaviour: attitudes, intentions, and perceived behavioural control. J. Experim. Social Psych. 1986; 22: 453-475.

6. Belgrave, F.Z., Randolph, S.M., Carter, C., Braithwaite, N., and Arrington, T. The impact of knowledge, norms, and self-efficacy on intentions to engage in AIDS-preventive behaviours among young incarcerated African American males. J. Black Psych. 1993; 19: 155-168.

7. Pattullo, A.L.S., Malonza, M. Kimani, G.G. Muthee, A. Otieno, P.A.O. Odhiambo, K., Moses, S. and Plummer, F.A. Survey of knowledge, behaviour and attitudes relating to HIV infection and AIDS among Kenyan secondary school students. AIDS CARE, 1994; 6: 173- 181 .

8. MacLachlan, M., Chimombe, M., and Mpemba, N. AIDS education for youth active learning: a school-based approach from Malawi. Inter. J. Educ. Develop. 1997; 17: 41-50.

9. Visser, MJ. The need for AIDS education in schools: an analysis of knowledge, attitudes and behavioural intentions of students. S. Afr. J. Educ. 1995, 15: 130-138.

10. Kasule, J., Mbizvo, M.T., Gupta, V., Fusakaniko, S., Mwateba, R., Mpanju-Shumbusho, W., Kinoti, S.H., and Padachy, J. Zimbabwean teenagers' knowledge of AIDS and other sexually transmitted diseases. East Afr. Med. J. 1997; 74: 76-81.

11. DiClemente, R.J., Boyer, C.B., \& Morales, E.S. Minorities and AIDS: knowledge, attitudes, and misconceptions among Black and Latino adolescents. Public Health Briefs 1988; 78: 55-57.

12. Hubley, J.H. AIDS in Africa: a challenge to health education. Health Educ. Res. 1988; 3: 41-47.

13. Scott, S.J., and Mercer, M.A. Understanding cultural obstacles to HIV/AIDS prevention in Africa. AIDS Education and Prevention 1994; 6: 81-89.

14. Airhihenbuwa, C.O. Perspectives on AIDS in Africa: strategies for prevention and control. AIDS Education and Prevention 1989; 1: 57-69.

Appendix 1

AIDS prevention behaviours questionnaire

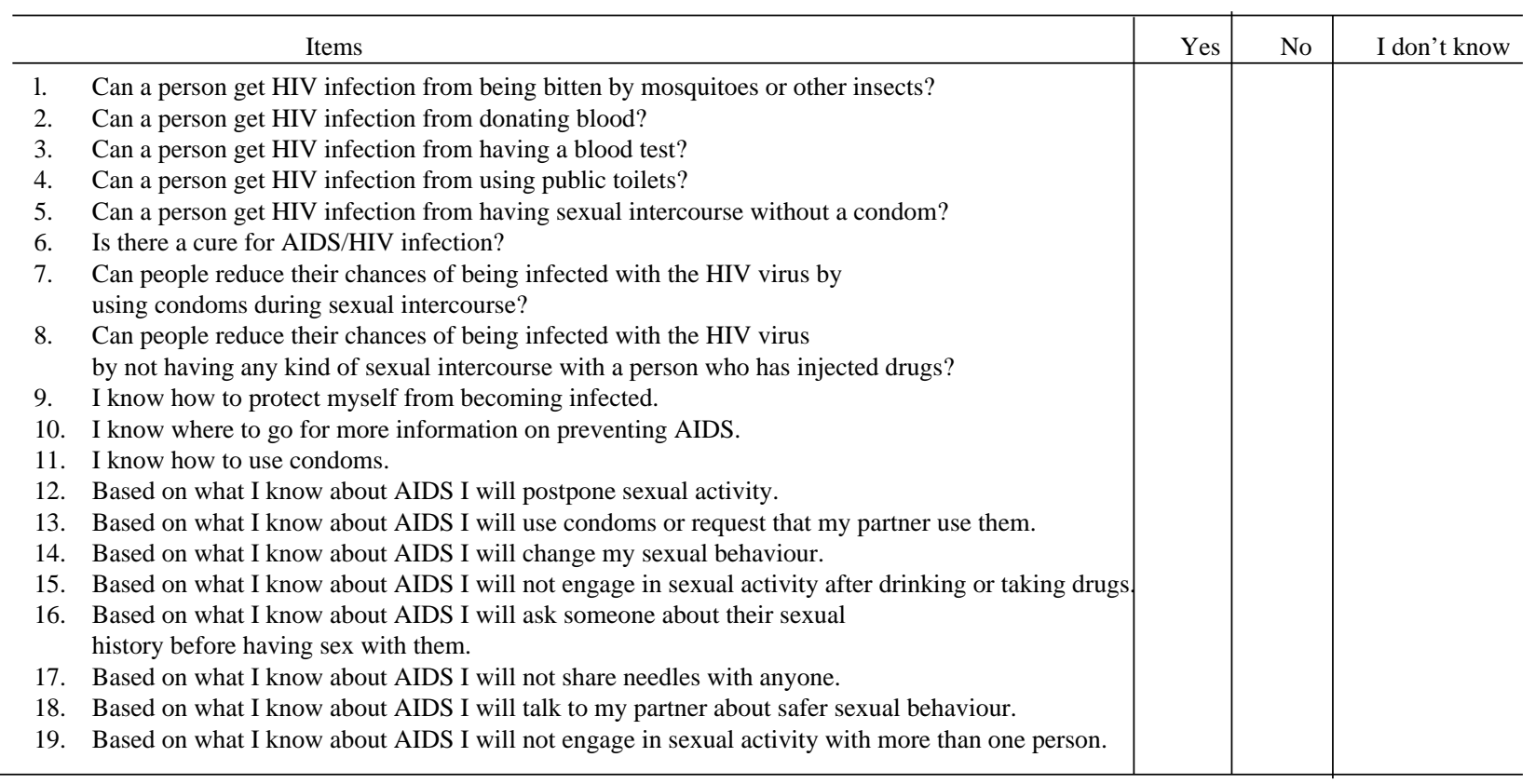

